\title{
La Reforma Administrativa: blancos imaginarios y arqueros inciertos
}

\section{J. Vilas Nogueira*}

Este articulo tiene su origen en mi intervención en el Seminario sobre la Reforma Administrativa ', pero no la reproduce exactamente, pues me ha parecido útil recoger algunas inspiraciones de algunos de los colegas intervinientes e introducir ciertas cuestiones, o precisar la formulación de algunas de las expuestas oralmente, como consecuencia de algunas manifestaciones de otros colegas, que me parecen equivocadas.

En primer lugar, a la vista de algunos desarrollos resulta conveniente, sino inexcusable, precisar edesde dónde" se hace esta intervención. Es una intervención de un profesor de ciencia política, consagrado preferentemente a la ciencia política básica. No es un discurso de un político ni de un experto o consultor. Es posible que la ciencia política básica no tenga mucha utilidad, incluso es posible que no tenga ninguna, pero está reconocida en la vigente institucionalización del saber, y no parece que sea uno de sus cultivadores el más adecuado para emitir un juicio a propósito de su utilidad. En cualquier caso, es rigurosamente no pertinente pedir "peras" de practicismo político o de expertisage (o saber aplicado) al colmo• de la ciencia política básica. La intervención del Sr. Secretario de Estado para las Administraciones Públicas, con irónica reticencia hacia la utilidad para los políticos de los desarrollos académicos, lo dejó muy claro. Lamentablemente algunos otros intervinientes no parecían tenerlo tan claro y pretendieron responder a ciertas críticas teóricas con la justificación de ciertas mejoras producidas en los procesos administrativos por consecuencia de inspiraciones reformistas asumidas ecléctica y pragmáticamente. Si estas mejoras son ciertas, todos debemos felicitarnos por ello, pero no necesariamente enervan las críticas teóricas.

En segundo lugar, por la misma razón de que estamos hablando de ciencia política, las palabras importan. En todas las ciencias la precisión del lenguaje es un objetivo deseable, y el grado de su consecución suele ser paralelo al grado de su cien- tificidad. Esto no siempre resulta cómodo ni aparece justificado para los profanos, que suelen tender a considerar este objetivo, estéril •nominalismo: Imagínese, sin embargo, qué quedaría de cualquier ciencia si le sustraemos la precisión del lenguaje. La ciencia políica, como escribió Sartori hace ya algún tiempo, debe también buscar la univocidad y la precisión de sus términos. Afortunadamente, en el campo de la reforma administrativa la situación es mejor que en otros terrenos de la Ciencia Política ${ }^{2}$. Con todo, las palabras utilizadas para designar las reformas de la Administración varían según los países. En España, sin duda, la palabra que ha encontrado más favor ha sido la de modernización (CANALES, 1994: 67). En este Seminario, Carrillo lo ha explicado como consecuencia de que entre nosotros el término modemización se ha utilizado ya desde el siglo XVIII como expresión de designios de equiparación con Europa, por ello con una carga valorativa positiva. Seguramente es verdad, lo que explicaría las traducciones de ciertos títulos muy influyentes ${ }^{3}$.

Pero también se ha usado la expresión •modernización administrativa, con un sentido específico. A diferencia de las reformas, que tienen un alcance y persiguen objetivos definidos, la modernización sería un proceso abierto, un proceso sin fin, de reajuste de las estructuras y, sobre todo, de los procesos administrativos, por lo que no puede afirmarse en ningún momento que haya llegado a su fin (NIETO, 1989) ni delimitarse claramente um contenido espećíico ${ }^{4}$. (En este Seminario, esta posición ha sido asumida claramente por el Secretario de Estado para las Administraciones Públicas, que ha llegado a decir que erradica sistemáticamente de los borradores de sus discursos la palabra reforma»). Ésta es también la posición que adoptamos Bastos BouBETa y yo (en un artículo pendiente de publicación). Creemos que deberían distinguirse las modificaciones en la actuación administrativa derivadas de la adaptación de las Admi- 
nistraciones públicas, como reacción a cambios en su entomo, social, económico o político, que llamamos modemización administrativa ${ }^{5}$, de aquellos otros procesos que suponen un intento deliberado de transformación, no meramente reactivo al entorno, sino con pretensión de modificarlo, ya sea mediante la mejora de los métodos y técnicas de funcionamiento en general, ya mediante la mejora del desempeño de los empleados públicos en particular, que llamamos reforma, en sentido estricto.

La pretensión de diferenciación conceptual no implica, en modo alguno, una pretensión, derivada, de establecer una cualquier jerarquía entre reforma y modernización. Es conocido que hay una corriente de la teoría de las organizaciones, con aplicaciones específicas al estudio de las organizaciones políticas, tanto a organizaciones administrativas como de otro tipo, por ejemplo, partidos políticos, que subraya la influencia del entorno en los procesos de cambio organizativo. Con frecuencia éstos obedecerían a shocks exógenos, cuya etiología puede vincularse al impacto de nuevas ideas (surgidas en el entorno de la organización), pero sobre todo de desarrollos tecnológicos o del juego político (o de poder) de actores relevantes del entorno. En cualquier caso y naturalmente, la distinción entre acción meramente reactiva y acción transformadora es relativa; en casos extremos, la frontera puede ser muy sutil; y pueden darse transiciones de una a otra, pero siempre pueden separarse conceptualmente.

Como ha sido señalado, entre otros, por WriGHT, (1994: 103110, y 1995: 7), los procesos de cambio que se desarrollan en el seno de las Administraciones públicas roccidentales" responden a muy diversas motivaciones y ofrecen tales variaciones, en dirección y énfasis, que hacen muy difícil un enfoque uniforme. El estudio de las "reformas administrativas" constituye en estos momentos una de las ramas más fértiles de las publicaciones sobre la Administración, debido a la gran cantidad de las emprendidas desde los años 60 (CAIDEN, 1991: vii) y a la no despreciable cantidad de recursos materiales puestos a disposición de los expertos por los gobiernos.

Pero si las reformas son tan distintas entre si $^{6}$, y si sólo una poco justificable amnesia histórica puede reducirlas a la contemporaneidad, iqué es lo que explica que se hable de un movimiento de reforma de la Administración como algo universal y distintivo de la contemporaneidad? Incluso, más allá de eso, la reforma administrativa ha sido, frecuentemente, presentada y percibida como una spanacea política. (WRIGHT, 1995: 8), un remedio universal, con virtudes tan diversas, como la capacidad de reducción del papel del Estado, de reconfiguración de la frontera entro lo público y lo privado, de erosión del semi-colectivismo social-demócrata, real o pretendidamente apoyado en las tendencias expansionistas de la burocracia y del presupuesto alentadas por los burócratas. La reforma, por el contrario, incrementaría el papel de la iniciativa individual (y de las organizaciones individualmente consideradas), acrecentaría las posibilidades de elección del consumidor y mejoraría la eficiencia de las organizaciones públicas (WRIGHT, 1995: 8, llega a comparar alguna retórica británica de las reformas con la publicidad de un laxante).

Hay una explicación genérica. Tendemos, y en España tanto o más que en cualquier otro sitio, a demandar del gobierno la solución de todos los problemas posibles (y de algunos imposibles), sin reparar en que, a veces, las demandas que formulamos son lógicamente inconsistentes, por contradictorias. Esta tendencia es más fuerte, naturalmente, en democracia (al fin y al cabo, ino hemos elegido al gobiemo para que solucione nuestros problemas?) y se ha potenciado, paradójicamente (paradójicamente, porque es uno de los objetivos de muchas reformas) con el Estado de bienestar. Podemos, así, exigir más servicios públicos, pero menos impuestos; mejores servicios, pero también más baratos; mayor efectividad pero también mayor transparencia, mayor diligencia, pero también mayor participación y consulta en el proceso de decisión (uno de los objetivos típicamente imposibles), mayor representatividad, pero también mayor atención al mérito como criterio de selección (WRIGHT, 1994: 106).

Pero también hay dos razones más específicas para esta percepción de la reforma administrativa como algo universal y distintivo de la contemporaneidad: la necesidad de limitación del gasto público y la moda. La primera y más importante es, como acabamos de decir, la creciente y acuciosa necesidad que han experimentado los Gobiernos de limitar el gasto público y, en particular, el déficit público, que ha alcanzado unos volúmenes que parecían poner en riesgo la misma persistencia de los sistemas establecidos, particularmente a través de la inducción de acelerados procesos inflacionarios. Desde la crisis económica de la primera mitad de los setenta, ha sido cada vez más frecuente la postulación de sterapias de adelgazamiento de las Administraciones Públicas. Quizá, el elemento común a todas las reformas es la prosecución de un abaratamiento de los costes de gobierno (PETERS, 1996b: 1). La necesidad de limitar el déficit público ha encontrado, además, una duplicación institucional en Europa Occidental, a causa de los objetivos económicos que se han fijado como requisitos para el acceso a la Unión Europea.

Esta necesidad ha dado lugar a dos tipos de respuesta: por un lado, la que se ha dado en llamar "neo-liberal, que se vinculó a los programas de la Premier Thatcher en el Reino Unido y del Presidente Reagan en los Estados Unidos. Una de las cosas más sorprendentes del predicamento que encuentran estos programas, en ciertos ámbitos académicos o de expertos, es que, particularmente en la formulación reaganista, no ofrecen nada teóricamente nuevo. Las suposiciones teóricas básicas habían sido anticipadas hace ya tiempo por la Escuela de Chicago, en particular por Milton Friedman. Las consecuencias prácticas eran la eliminación, en cuanto fuese posible, de todo gasto público; y cuando no fuese posible la eliminación, su restricción 
en base a criterios de rendimiento, evaluado con arreglo a los parámetros propios del modelo del mercado.

En cualquier caso, aquellos programas generan la ilusión de haber encontrado un modelo de Estado, alternativo y sucesor del Estado de bienestar. Muy abruptamente, el argumento es que el Estado de bienestar comporta un modelo de asunción de competencias y de gestión insostenible en la situación contemporánea. En las formulaciones más radicales y más congruentes con la inspiración teórica básica (esto es muy patente en Friedman) hay también un énfasis moral, en el sentido de afirmar el carácter comuptor del providente paternalismo del Estado de bienestar, que inhibe las energías creadoras y la responsabilidad individuales.

A pesar de que los modelos thatcheriano y reaganista distan de haber tenido éxito (o si se quiere decir más comedidamente, han tenido un éxito sólo relativo), y en el caso americano la constatación del fracaso obligó a una rectificación bajo el mandato del mismo Reagan, su legitimación inicial se ha beneficiado de una cierta inercia. Sin embargo, por ningún lado se puede encontrar un emodelo neo-liberal. que pueda competir en definición y difusión (por lo menos, en Europa) con el Estado de bienestar (aunque, como es esperable, la definición de este modelo incluya también notorias incertidumbres).

Pero las mismas exigencias de limitación del gasto público operaron también respecto de Gobiernos social-demócratas. Dado que estos Gobiemos están programáticamente cerrados a los valores y los objetivos "neo-liberales", la presión reductora del gasto público se centró aquí en esfuerzos por la mejora de gestión y la optimización del empleo de los recursos, a través de la reforma de estructuras y procesos de la Administración.

Independientemente de la opción que cada uno pueda hacer por fórmulas neo-liberales o social-demócratas, la crítica neo-liberal, en sus formulaciones más instrumentales y de combate, que han tenido relativo éxito en España ${ }^{7}$, ha incurrido en evidente injusticia en su crítica del Estado de bienestar, al presentar como consecuencia de deficiencias constitutivas del modelo, en general y en abstracto, dificultades que, por el contrario, derivan del contexto histórico de estos últimos años, y que se pueden reducir a dos grandes causas: la evolución demográfica, que ha determinado unas pirámides demográficas no ya achatadas, sino invertidas, y las muy elevadas tasas de desempleo, generadas (por lo menos, en parte) por el progreso tecnológico (naturalmente, a medio y largo plazo el progreso tecnológico no tiene por qué eliminar empleo; pero a corto plazo suele hacerlo). Estas evoluciones han roto el equilibrio de los buenos tiempos del Estado de bienestar, entre población contribuyente al mantenimiento de los servicios sociales y población beneficiaria de los mismos. La paradoja resultante es que el Estado de bienestar se hace imposible o difícil cuando parece más necesario ${ }^{8}$.
En cualquier caso, a estas dos inspiraciones fundamentales, neo-liberal, por una parte, y de salvaguarda, por la optimización de la gestión, del Estado de bienestar, por otra, se pueden vincular dos grandes tipos de reforma (para una clasificación detallada de los programas de reforma, ver WRIGHT, 1994: 108 ss.).

La propuesta neo-liberal tiene como objetivo la reducción o adelgazamiento del Estado. El Estado sería una suerte de mal necesario y, por tanto, debería ser reducido al mínimo. Sería malo en el terreno moral, en cuanto inhibidor de los valores y la responsabilidad individuales, y en cuanto enemigo formidable, al menos potencialmente, de la libertad individual. Sería malo en el terreno económico, pues produciría y asignaría recursos menos eficientemente que la empresa privada y el mercado. Desde luego, esta posición es consistente con sus postulados. Sin embargo, el problema teórico se halla en la determinación y en la justificación de ese "mínimo de Estado. ¿Qué servicios o bienes deben ser suministrados de modo público y por qué? Como es sabido, hay una respuesta de hace ya bastantes años. SAMUELSON (1954) intentó formular una teoría pura del gasto público, a partir de la noción de abien colectivon. En pocas palabras, y prescindiendo del sofisticamiento formal, existirían algunos bienes cuyo consumo por un determinado consumidor no excluye el consumo simultáneo por consumidores alternativos, ni disminuye su utilidad (el pollo que yo como no puede ser comido por mi vecino, pero la carretera que yo uso puede ser utilizada por mi vecino, sin que esa utilización excluya ni perjudique mi capacidad de uso). Los bienes colectivos son producidos menos eficientemente por las organizaciones privadas que por el Estado u otros órganos públicos (y al límite no serán producidos en absoluto, dada la carencia de incentivos para su producción en régimen de propiedad privada) (sobre esta cuestión y las estrategias políticas de gasto público, en general, ver Vilas Nogueira, 1996).

Pero la clase de los "bienes colectivos" es realmente reducida en número, y cada vez parece serlo más: resulta difícil convencer al automovilista, atrapado durante horas en un atasco de la circulación, o al ciudadano comprometido en un pleito, que ve pasar años y años sin que recaiga sentencia, como consecuencia del exceso de trabajo de los tribunales, de la pertinencia de esta categoría. Ya MARGolis (1955) apenas reconocía el carácter de bien colectivo a la defensa nacional y al alumbrado público. Al margen, pues, de las virtudes formales del modelo de Samueison (1954) (y de la posibilidad de utilizarlo como atipo idealn, en el sentido weberiano, o como pauta normativa), incluso el liberal más entusiasta ha de reconocer que en la realidad empírica difícilmente se encuentran Estados que reduzcan su acción a la provisión de •bienes colectivosn, así definidos.

Las propuestas neo-liberales encuentran también un problema práctico, de facticidad. En el terreno de la teoría formal, 
HolCOmBe (1978) presentó un modelo de opción electoral que favorece ineluctablemente al partido que ofrece mayor nivel de gasto público. También, al margen de la teoría formal, uno de los problemas a los que se enfrenta un programa de reducción. de Estado, en España y en países que en este aspecto se le parezcan, es la previsible dificultad de obtener un apoyo electoral sostenido. El problema no es sólo, ni siquiera preferentemente, ideológico, como con mayor o menor ingenuidad sostienen los defensores de estas políticas. El problema se halla en el gran número de electores que perciben sus salarios del sector público, en el gran número de electores que perciben ingresos de transferencias del sector público (pensionistas de diversos tipos, perceptores de subsidios de paro, etc.), en el considerable número de electores cuyos ingresos, aunque no sean salarios o transferencias del sector público, son muy dependientes, aunque sea de modo mediato, de la actividad de este sector, por lo que, muy racionalmente, nada ideológicamente, estos electores pueden obrar con arreglo a una inspiración de aversión al riesgo" ante la expectativa de reducción del sector público. Parafraseando a WRIGHT (1995), haría falta un Estado despótico para poder establecer un Estado liberal (!).

La segunda razón de la percepción de la reforma administrativa como algo universal y distintivo de la contemporaneidad se vincula a la siempre difícil explicación de las determinaciones de las modas. La reforma administrativa está de moda y ningún gobierno que se precie puede ignorarla (WRiGHT, 1995: 8). Además, en la contemporaneidad las modas tienen virtualidad planetaria. Como algunos famosos refrescos, como la mayor parte de los productos de consumo de masas, la reforma tiene difusión universal. Ciertamente, los agentes y los procesos de difusión de las reformas administrativas son diferentes de los de difusión de las bebidas refrescantes; pero no son inidentificables: por un lado, la intemacionalización del saber institucionalizado ha alcanzado de pleno a las ciencias sociales (hasta hace poco notablemente retrasadas en este aspecto en relación a las ciencias físico-matemáticas); por otro lado, la insistencia en las constricciones de las realidades macroeconómicas sobre las políticas realmente posibles potencian la percepción de que los países más desarrollados son el modelo a seguir, desconsiderando o marginando otros aspectos de tipo ideológico. o de contextura nacional, lo que acrece extraordinariamente la eficacia de los procesos de difusión; finalmente, la cada vez mayor importancia de organizaciones regionales supraestatales o internacionales (WRIGHT, 1994: 108), que han generado burocracias propias cada vez más poderosas, es otro instrumento favorecedor de los procesos de difusión de las reformas, a través de las urgencias, reales unas veces, presuntas otras, de homogeneización de las Administraciones nacionales (sobre la incidencia del proceso de comunitarización europea, ver WRIGHT 1994: 104-105).
Más en concreto, los programas de reforma que se centran en la gestión son los más condicionados por los imperativos de las modas. Este condicionamiento dista de ser espontáneo. Tanto en referencia al ámbito de la gestión pública como de la privada existen una serie de guris, con su corte de asesores académicos à la page que producen (guris, pero con disposición industrial.) •nuevas ideas" para una mejor gestión. Ideas legitimadas con palabras muy cargadas positivamente, pero poco precisas, como eficiencia, eficacia, calidad, productividad, etc. (ABRAHAmSON, 1996). Estos guris venden sus "saberes" en un lucrativo mercado que se beneficia de la demanda de innovaciones en la gestión por parte de políticos buscadores de votos y de políticos y altos burócratas deseosos de acrecer su legitimación como recurso de promoción profesional. Esto explica la fugacidad de muchas de las propuestas que se hacen en este terreno, siempre expuestas a ser superadas por otras umás avanzadas. o novedosas (RIGBY, 1993, una de las voces más críticas de estos desarrollos, ha expuesto un esquema del ciclo vital de estas "teorías" innovadoras de la gestión; para la última moda de gestión privada, ver HaRARI, 1997).

Se ha llegado así a la postulación de objetivos comunes para cualquier reforma administrativa, independientemente del contexto nacional, lo que comporta la suposición implícita de que cualquier estructura o procedimiento que haya tenido éxito en un sistema administrativo dado lo tendrá igualmente en cualquier otro. Lo llamativo no es que esta suposición sea compartida por la mayor parte de los líderes políticos (para quienes la reforma administrativa suele ser, fundamentalmente, un recurso legitimador), sino también por bastantes estudiosos, de los que cabría esperar la conciencia de que tal simplista optimismo peca de irrealista, pues las pautas estructurales y funcionales de la Administración pública en cada país, reflejo de diversas tradiciones administrativas y diferentes culturas políticas nacionales, no siempre son compatibles, en mayor o menor grado, con cualesquiera inspiraciones exteriores (PETERS, 1996b: 3).

\section{Gestión pública versus gestión privada}

Aunque la legitimidad de una distinción radical entre sistemas administrativos públicos y "sistemas administrativos privados. sea una cuestión polémica en la ciencia política, gran parte de la bibliografía sobre la reforma administrativa se basa en la diferenciación y contraposición entre eel modelo de gestión pública y el modelo de gestión privada. Esta contraposición no es sólo relevante para las posiciones neo-liberales, como legitimadora de la rreducción de Estado; lo es más todavía para las 
posiciones socialdemócratas o eclécticas, o simplemente pragmáticas, cuyo objetivo fundamental no es tanto seducir Estado. como •mejorar gestión. Por lo general, la contraposición entre un emodelo de gestión pública y otro de gestión privada se presenta de modo apriorístico, por tanto, sin ninguna justificación. Conviene, pues, reflexionar sobre sus implicaciones y sobre los rasgos. que explícitamente se atribuyen a uno y otro -modelos para evaluar el grado de pertinencia de la contraposición y los limites de su aplicabilidad.

Obviamente, se implica que el carácer público o privado es fundamental para la determinación del tipo de gestión. Otras circunstancias posiblemente influyentes: tradiciones nacionales, tamaño de la organización, culturas políticas o culturas organizativas" particulares, etc., o son enteramente desconsideradas o se les atribuye un valor completamente secundario. Se implica que hay un modelo. de gestión pública y un modelo. de gestión privada y si existen diferencias de modos de gestión entre organizaciones privadas o si existen diferencias de modos de gestión entre organizaciones públicas, de nuevo, o son enteramente desconsideradas o se les atribuye un valor completamente secundario. Por otra parte, conviene subrayar que cuando se habla, con estos propósitos, de gestión privada, la referencia "privadan tiene un sentido mucho más restrictivo que en otras utilizaciones de la comprensión de la diferenciación entre público y privado. La gestión privada quiere decir, en esta bibliografía, gestión de organizaciones que persiguen finalidades de ganancia económica: corporaciones o empresas industriales o comerciales, produzcan o comercialicen productos materiales o servicios (las propuestas de comunitarización de la gestión de servicios, de voluntariado social, etc., en general, lo que algunos han calificado como alibertarianismo contemporáneo, no tienen nada que ver con la postulación del modelo de -gestión privada).

Esta simplista consideración de una contraposición entre "gestión pública" y "gestión privada" es más llamativa, en muchos de los escritos sobre la reforma, en relación al primer término de la pareja que al segundo, pues ha de suponerse que sus autores han de conocer mejor las organizaciones públicas y sus modelos de gestión que las privadas. Es así, porque cualquier estudiante, incluso no particularmente aventajado, sabe que hay distintos sistemas administrativos, en el mundo "occidental. desarrollado. Aun en la posición más reduccionista habría que distinguir por lo menos dos: un modelo americano" de Administración Pública, con un sistema de reclutamiento de personal dependiente de los procesos electorales políticos, con estructuras de carrera y salariales muy diversificadas y flexibles, con ostensible vinculación a grupos de interés y un modelo *europeo- (PETERS, 1991), con una estricta y homogénea regulación normativa, estructuras de carrera y salariales rígidas y uniformes, garantías legales de permanencia de los funcionarios en sus puestos, y una tradición formal de ausencia de participación directa de los funcionarios, en tanto tales, en la decisión política ${ }^{9}$. Que respecto de sistemas tan diferentes se puedan postular modelos o directrices uniformes de reforma no parece muy plausible.

La siguiente implicación es que la gestión privada ofrece una eficacia y eficiencia superiores a la gestión pública. También aquí se desconsideran peculiaridades nacionales o de otro tipo. Por ejemplo, es posible que este axioma sea consistente con la historia y la realidad presente norteamericanas. Resulta menos evidente que sea consistente con la española. Si se acepta el axioma, las políticas posibles deseables son dos:

1. Reducir todo lo que se pueda el ámbito de la gestión pública en favor de la gestión privada. Es la posición tradicional del liberalismo económico. Dejando aparte los economistas clásico y neo-clásicos, se puede fundamentar teóricamente este enfoque en el intento, ya citado, de $S_{A}$ MUELSON (y otros muchos autores en su tradición) de reducir los fines de la actuación de las organizaciones públicas a la provisión de abienes colectivos, o en la Escuela de Chicago con Milton Friedman, como autor más conocido y beligerante, que enfatiza sobre todo en la superioridad del mercado como mecanismo de asignación de bienes. A inspiraciones de esta Escuela se han atribuido sustancialmente las políticas del General Pinochet en Chile, de la Premier Thatcher en el Reino Unido, o del presidente Reagan en los Estados Unidos, que tuvieron un éxito diferente según los casos (posiblemente de más a menos en el orden en que aquí son enumeradas).

2. «Privatizar" la gestión pública. Dada la superioridad de las técnicas y modos de gestión privada, sería deseable importarlos en el ámbito de la gestión pública. Ésta es probablemente la orientación dominante en Europa Occidental en los últimos años, y ésta es la orientación que presenta mayores inconsistencias lógicas. Veamos, si hay dos modelos contrapuestos de gestión, pública y privada, que no reconocen diferencias sustanciales, en el interior de cada uno de ellos, por razón de tiempo, lugar o cualquiera otra circunstancia, y si no se nos dice nada sobre la génesis y evolución de estos dos tipos de gestión, habrá que concluir lógicamente que el modelo de gestión privada deriva de la estructura y finalidades propias de las organizaciones privadas, y el modelo de gestión pública deriva de la estructura y finalidades propias de las organizaciones públicas. Por tanto, a partir de supuestos tan simplistas, el intento de privatizar la gestión pública es inconsistente lógicamente; y aunque la consistencia lógica no sea condición suficiente para el éxito de cualquier política, sí es probablemente condición necesaria. 
Esta inconsistencia lógica se manifiesta en los resultados paradójicos a que puede abocar la utilización de ciertas técnicas cuando se ignora la diferente teleología de las organizaciones públicas y privadas. Una ilustración concreta puede encontrarse en la "manía" evaluadora, aplicada a la Administración. Por un lado, la mayor complejidad de los outputs administrativos, respecto de los de la empresa privada, determina que el sistema (si no recibe alguna sayuda. de mecanismos de mercado) genere fácilmente perversiones que ahagan peor el remedio que la enfermedad. Pero, sobre todo, la evaluación puede revelar no sólo disparidades de rendimiento entre distintas unidades administrativas, sino también disparidades en el tratamiento de distintos sectores de población, usuaria o consumidora de servicios públicos (WRIGHT, 1995: 10). Mientras una similar constatación en el terreno de las organizaciones privadas no tiene por qué tener consecuencias dramáticas (puede incluso no tener ninguna consecuencia, pues las organizaciones privadas son libres de elegir el público al que dirigen sus productos o servicios), en la Administración (que no disfruta de igual libertad) el resultado será el surgimiento, o la alimentación, de presiones políticas para la eliminación de aquellas diferencias. Como resultado, puede producirse, por un lado, que una técnica pensada para la reducción de los costes de gobierno o administración alimente presiones expansivas de aquellos costes. Por otro lado, puede favorecer la percepción de agravios relativos, que generen o potencien litigios, en forma de demandas administrativas o judiciales, contra la Administración.

En verdad, la lógica de muchos de los programas de reforma, implican la consecuencia de la expansión de los litigios contra la Administración. Y aunque a algún administrativista le pueda parecer una consecuencia deseable, o cuando menos trivial, no veo cómo, para un nivel dado de recursos afectados al mantenimiento de los servicios públicos, el incremento de las pretensiones litigiosas contra la Administración pueda mejorar el rendimiento de los servicios públicos o, si se quiere decir en términos más tradicionales, el grado de satisfacción del interés general ${ }^{10}$. Incidentalmente, puede suponerse, en la línea de una vieja tradición crítica, que el acrecimiento de la litigiosidad frente a la Administración, con la inseparable consecuencia de la erosión de su legitimidad como aparato al servicio del interés gene$\mathrm{ral}$, favorecerá mayormente a aquellos ciudadanos dotados de mayores recursos económicos y culturales, peligro nada imaginario a la vista de la situación en algunos de los países más desarrollados. Finalmente, si la Administración merece ser tratada como un particular, ¿qué razón hay para mantenerla?; si la Administración es contemplada como un potencial, y formidable, enemigo de los ciudadanos, ¿por qué no suprimirla?

El mismo WRIGHT (1995) destaca la paradoja de que la postulación de procedimientos evaluadores disminuye la autonomía de los cuerpos de funcionarios, acreciendo el intervencionismo del Estado. Probablemente, el problema no es el grado de intervencionismo, sino los actores y los procedimientos por los que se actúa. Así, el énfasis gerencialista, derivado de la importación del modelo de agestión privada conduce a la erosión de los mecanismos y consecuencias de la responsabilidad política. Aunque estos mecanismos y consecuencias no sean siempre de fácil determinación tienen importancia crucial en una sociedad democrática y, obviamente y coeteris paribus, cuanto más se acrecen la autonomía y responsabilidad gerenciales, más se difumina la responsabilidad política. Esta poco deseable consecuencia se vincula a la cuestión de la efficiencia. Los programas de reforma pretenden sensibilizar a los funcionarios públicos a los imperativos de la eficiencia; ¿pero cómo se define la eficiencia? (WRIGHT, 1995: 11). No se necesita mucha sofisticación para comprender que esta definición no es fácil, dado que aplicada a la provisión de bienes públicos implica externalidades políticas y sociales complejas. La Administración pública no vende, meramente, una serie desagregada de productos. Precisa hallar puntos de equilibrio entre múltiples requerimientos interconectados, y frecuentemente en conflicto. Y una de las cuestiones que afectan a aquellos equilibrios es, si cabe, la maximización de la eficiencia de las organizaciones públicas ignorando el ethos del servicio público. Si los ciudadanos son transformados en clientes, no hay por qué esperar que los funcionarios sean otra cosa que productores reducidos a la lógica y a las gratificaciones del mercado privado, y en tanto tales insensibles a las pautas y a los valores tradicionalmente incorporados al servicio público (cabe reiterar la anterior pregunta, ¿para qué, entonces, la Administración pública?).

La popularidad, pese a ello, de las inspiraciones "privatistas. es, probablemente, consecuencia de una simbiosis entre políticos reformadores y expertos reformadores, interesados, unos y otros, más en los beneficios de la apariencia del cambio, que comprometidos en los riesgos de cambios reales. En la realidad, al contrario de lo que se pretende, los modelos de gestión privada, y la bondad de sus resultados, divergen notoriamente según los paises y las épocas, no menos que los modelos de organización y gestión públicas. Los propugnadores de reformas en esta dirección deberían buscar, y exhibir, algún mayor conocimiento de la bibliografía existente sobre los problemas y las modalidades de la agestión privada. Deberían tener en cuenta, por ejemplo, que el amodelo de gestión privada", que parecen implicar, por lo menos en España, referido a empresas de dimensión nacional (e implícitamente de tamaño mediano) productoras de un solo producto (o de unos pocos homogéneos) pierde progresivamente relevancia, parece que de modo inexorable, ante (gigantescas) empresas multinacionales multiproducto. Pero, sobre todo, deberían procurar alguna simetría en los términos de comparación, evitando comparar el emodelo. (y no la realidad) del mercado con la realidad. (y no el modelo) de la Administración pública. 


\section{Autoridad y monopolio}

La caracterización más obvia de las organizaciones públicas está en su capacidad de utilizar recursos de autoridad, tanto en la captación de recursos como en la asignación de sus productos y naturalmente, también, en la disposición o agenciamiento de sus estructuras y procesos de funcionamiento. A nuestros efectos, bastará con definir la autoridad, por remisión a Weber, como la capacidad monopolística de recurrir legítimamente al uso de la violencia física. Probablemente, se puede pensar en una sociedad sin autoridad, pero razonablemente hay que ser escéptico ante su posibilidad real, dado que todas las sociedades históricamente conocidas presentan algunos fenómenos de autoridad. En cambio, ninguno de los objetivos que son actualmente perseguidos, o lo han sido históricamente, por organizaciones públicas, esto es, organizaciones investidas, inmediata o mediatamente, de recursos de autoridad, excluyen su prosecución en determinadas épocas o lugares por organizaciones privadas.

En cualquier caso, para la conciencia contemporánea (y esto es, evidentemente, un modo de hablar figurado, pues no creo en ninguna conciencia colectiva) puede distinguirse con relativa facilidad (que no excluye incertidumbres y zonas grises) entre actividades públicas "constitutivamente* autoritarias (la defensa nacional, la justicia, el régimen de la propiedad, la emisión y el régimen de la moneda, etc.) y otras actividades públicas que son tales por razones de oportunidad.

En la contemporaneidad estas razones de oportunidad se concretan en diversos tipos de actividad estatal. Por un lado, se ha producido, en bastantes países, una muy importante actividad reconómica. (quiero decir, de producción de bienes y servicios en los que no es perceptible prima facie ninguna peculiaridad respecto de los producidos por la empresa privada) del Estado, sus organizaciones o agencias. La justificación de esta actividad obedece a plurales razones, históricamente convergentes. Desde la incapacidad o renuencia del capital privado a afrontar inversiones muy importantes a motivaciones de seguridad nacional (por ejemplo, los ferrocarriles, en la etapa inicial de este medio de comunicación), pasando por inspiraciones socializantes (la nacionalización de la banca u otras actividades financieras) o ideales de autarquía económica nacionalista (por ejemplo, el INI franquista). Por otro lado, en la generalidad de los países, la Administración desempeña una importante actividad prestacional, como consecuencia de la postulación de ciertos objetivos de temperamento de las desigualdades, o 0 .justicia social. (prestaciones asistenciales: seguros sociales, servicios de medicina pública), o de garantía de las capacidades ciudadanas (servicios de enseñanza pública, que no sólo persiguen la mitigación de los efectos sociales de las desigualdades económicas, sino también, en algunos paises preferentemente, la defensa frente a ideologias particulares vehiculables por la escuela privada, etc.).

Estos últimos objetivos se condensan en el ideal del welfare state, y aunque analíticamente son perfectamente discemibles de lo que he llamado actividad económica. del Estado, lo cierto es que en la realidad histórica han tendido a manifestarse confundidamente. Por ello, con mucha frecuencia los enfoques -reformistas dirigen una crítica uniforme a tipos de actividad estatal muy diferentes. Ciertamente, tienen algo en común, son actividades no econstitutivamente, autoritarias, pero ya hemos visto los límites de cualquier intento de definición teórica de la actividad pública. No parece haber actualmente muchas razones para defender que el Estado, o más en general organizaciones públicas, al margen de los criterios de la eficiencia, definida sobre parámetros estrictamente económicos (quiere decirse, privados), mantenga una banca comercial o de servicios, produzca automóviles o abonos nitrogenados o se encargue del transporte aéreo. Pero esta constatación nada tiene que ver con el juicio que merezca la actividad prestacional de las Administraciones públicas. Mientras que en el primer caso puede cuestionarse seriamente la pertinencia de la actividad (ya que ni los objetivos de igualación social ni de garantía de la independencia nacional parecen confirmados por la experiencia), en el segundo, el argumento es de otro tipo (en España, y en otros países, dista de haberse probado que la ausencia de un sistema público de sanidad o de pensiones garantice a una gran parte de la población unas prestaciones suficientes; con arreglo a estándares culturalmente aceptables en la contemporaneidad). Aquí el argumento, el gran argumento, parece ser "meramenten de facticidad del sistema, el imperativo de reducir el enorme crecimiento experimentado por el gasto público, que ha generado un déficit igualmente creciente, induciendo procesos inflacionarios, con perjuicio del cuadro económico general.

Las respuestas son, como antes, dos. Una, más radical, niega la pertinencia de que el Estado u otras organizaciones públicas asuman la provisión de prestaciones de previsión, sanitarias, de enseñanza, etc. Es la respuesta liberal, pero no sólo es la respuesta liberal. Por lo menos en España, donde la Iglesia Católica ha jugado siempre un papel tan relevante, debería recordarse que también es la respuesta de la Iglesia (otra cosa es que la doctrina social de la Iglesia sea realizable en régimen democrático). Las confusiones de la izquierda y la derecha españolas cuando critican o defienden políticas neo-liberales. evidencian que Adam Smith y León XIII con sus filosofias enteramente opuestas tienen un punto en común (probablemente el único): ambos son antiestatistas. El primero, desde la defensa de la espontaneidad del mercado; el segundo, desde la proclamación de la subsidiariedad del Estado (el problema de la derecha española es que, en su versión ‘constitucionaln, se alimentó 
de la parasitización de la Administración Pública, de verdad, de verdad, no puede estar con León XIII).

La otra respuesta es la sumisión de las organizaciones públicas prestacionales al mercado. No se cuestiona que el Estado u otras organizaciones públicas desempeñen tareas de provisión de ciertos bienes o servicios, sino que lo hagan en régimen de monopolio o de concurrencia desleal. Esta dirección de las reformas (con la que, desde luego, simpatizo) induce a pensar que las deficiencias de la agestión pública. no se deben tanto a razones de estructura o dinámica de las propias organizaciones como a des-incentivos derivados de la situación de monopolio (ver NisKanen, 1971). Los vicios que se suelen achacar a la actividad "pública: pereza de la gestión, des-economías, cuando no abierto despilfarro de recursos, indiferencia ante las preferencias de los consumidores o clientes, se deben, en realidad, no al carácter público o privado de la organización, sino a su situación monopolística ${ }^{11}$.

\section{La burocracia: vicios propios y culpas ajenas}

Muy evidentemente, desde su acuñación el neologismo •burocraciaw incorporó un significado disvalorativo. La mayor parte de la bibliografía que se refiere a la burocracia es muy crítica (Veblen, 1904; Mises, 1962; Merton, 1992 (1968); Hummel, 1994). Esta visión negativa está también muy presente en la percepción del público en general: las burocracias tienen fama de comuptas, despilfarradoras, torpes y tiránicas; sobre todo se les acusa de falta de agilidad en la gestión y de insensibilidad hacia las necesidades de los ciudadanos. Desde luego, ha habido numerosos intentos para determinar un concepto de burocracia que eludiese componentes valorativos. Algunas veces, y en algunos campos, estos intentos tuvieron cierto éxito; pero en la mayor parte de la bibliografía la burocracia se utiliza con un significado peyorativo (entre las pocas excepciones BLAU Y MEYER, 1971; y GOODSELL, 1994, además de Weber, claro).

Lógicamente, poco bueno se puede esperar de lo que se reputa constitutivamente malo. Para los expertos en las reformas la burocracia es uno de los enemigos a batir. Seguramente tendría escasa utilidad aducir, en sentido contrario, argumentos favorables a las burocracias. Pero sí puede tener alguna detenerse en la diagnosis de la etiología de los males de la burocracia, pues en este terreno sus críticos suelen adolecer de inconsistencia lógica.

El núcleo de mi argumento es que los males más importantes de las burocracias no nacen de las propias organizaciones $\mathrm{ni}$ del personal burocrático, sino de la definición de las reglas de actuación de las organizaciones públicas que se formulan en instancias anteriores (lógicamente) y superiores (en el plano formal de la autoridad) a la actuación burocrática, esto, es, al nivel de la legislación, que es decidida, precisamente, por el personal político. Por tanto, acabar con la burocracia o remediar sus males no puede ser tarea de la reforma administrativa, sino de la reforma de las pautas del sistema político, al nivel de sus actores, sistemáticamente, más importantes, los legisladores (muy abruptamente, los políticos que pretenden eludir sus responsabilidades culpando a la burocracia o son tontos o son cínicos).

Veamos algunas ilustraciones. Se suele reprochar a la burocracia ritualismo, formalismo, impersonalidad, insensibilidad ante las particularidades de cada caso, etc. No es difícil descubrir que estos rasgos son consecuencia, sin duda poco deseables, pero consecuencia del principio de legalidad de la actuación de la Administración. Los legisladores no confían, o legislan como si no confiasen, en los ejecutores de las normas $y$, en consecuencia, intentan vincular sus decisiones al máximo del único modo que pueden hacerlo los legisladores, extremando la generalidad, la formalidad y la impersonalidad de los criterios de la recta actuación burocrática. Echar la culpa a los ejecutores de las constricciones a que los someten los legisladores es un cómodo expediente, pero es muy poco plausible. $\mathrm{Pa}$ radójicamente la insistencia "reformista. en algunos tópicos, expresados con diversas consignas, pero que presentan el elemento común de intentar robustecer la posición de los usuarios, consumidores o clientes presiona en el sentido de una mayor sburocratización. de la acción pública. En efecto, dado que un supuesto común a la totalidad de las organizaciones públicas, o cuando menos a su inmensa mayoría, es que consumen recursos obtenidos por vía de autoridad del común de los ciudadanos (aunque no siempre con igual incidencia sobre los diversos grupos sociales; es llamativo el poco interés que se concede en la Ciencia Política a los análisis de la distribución real -que suele distar de ser uniforme y neutral para cada tipo de organización y para cada tipo de output- de las cargas de financiación), hay un sentimiento generalizado de que los productos o rendimientos de la acción pública no pueden ser atribuidos discrecionalmente.

En un nivel más concreto, se suele achacar a los burócratas una perversa función de maximizadores del gasto (o del presupuesto, si se prefiere). Estos argumentos son presentados a veces en cuadros melodramáticos, de modo que los burócratas, individuos egoístas descomprometidos con el interés público y entregados sólo a aspiraciones corporativas, utilizarían su know how profesional y las ventajas derivadas de su posición estable y consolidada en las cimas de las estructuras organizativas para obtener de sus financiadores (sponsors), esto es de los legisladores, mayo- 
res recursos de los que exigiría un funcionamiento eficiente. Esta visión puede tener en algunos casos alguna correspondencia con la realidad, pero formulada en términos tan generales es, cuando más, sólo una media verdad.

Es una media verdad, en primer lugar, porque los incentivos para la maximización del gasto y las conductas de maximización del gasto no son exclusivas de los burócratas. Como hemos visto más arriba, cualquiera sabe, si lo quiere saber, que los políticos electos están sometidos a muchas y muy fuertes presiones y tienen muy poderosos incentivos para maximizar el gasto (podría sospecharse que, con frecuencia, utilizan a los burócratas como mera coartada para eludir sus responsabilidades). También cualquiera sabe que puede haber incentivos para la maximización del gasto para responsables de unidades organizativas en organizaciones no burocráticas.

El problema no reside en el carácter burocrático o no de la organización, sino en el diseño de oportunidades e incentivos de gastos y economías. Hay incentivos al gasto, al "malgasto", de recursos que son atribuibles a las reglas fundamentales de la acción pública determinadas por los legisladores. Se trata de reglas asociadas al principio de especificidad de las consignaciones presupuestarias ("para qué voy a ahorrar dinero en calefacción si no me lo puedo gastar en teléfono, que es donde realmente lo necesito.) y a la anualidad del presupuesto, que suponen que los créditos presupuestarios no comprometidos en el año son anulados («me sobra dinero para adquisición de material informático, pero como no me lo puedo guardar para el año próximo, me lo gastaré de cualquier modo"). Todo el que tenga un mínimo conocimiento de nuestra Administración sabe que llegado noviembre se inicia una carrera, incluso una enloquecida carrera, para agotar, como sea, el presupuesto. Todo incentiva a ello: desde el punto de vista de la evaluación global de una administración el grado de ejecución del presupuesto es utilizado general y acríticamente como un indicio de buena gestión. Pero, además, desde la posición del responsable de cualquier unidad con autonomía de gasto, no sólo el no agotar el presupuesto supone un elemento negativo para la evaluación de la gestión actual, sino que prorrogará siniestramente su eficacia a la hora de negociar las consignaciones para el próximo presupuesto: "cómo pide Vd. más si el año pasado no fue "capaz" de gastar lo que le dimos?. Todo se conjura para gastar mal y pronto. A este propósito, la efectista crítica de OSBORNE y GAFBLER, 1994 (1992) tiene toda la razón. Pero repito, no es un problema del modo, el estilo, la técnica o la calidad de la gestión burocrática, sino de las constricciones externas, realmente nocivas en este caso, que se imponen a los gestores.

\section{Pero, ¿existe la burocracia? (como un actor con entidad social)}

Cuestión todavía más seria es la de si podemos hablar, en la realidad española contemporánea, de la burocracia como un actor político con alguna entidad social (quiere decirse como algo más que la designación colectiva de los titulares de ciertos roles de gobiemo o administración). La duda puede resultar llamativa, pues (casi) todo el mundo da por supuesto su existencia. Sin embargo, no es fácil encontrar definiciones de la burocracia que sean a la vez consistentes lógicamente y operacionales empíricamente.

En nota anterior, he citado la opinión de Rose (1991: 13), que comparto, de la habitual confusión en la Europa continental (pese al :modelo" weberiano, digo yo) de políticos electos y burócratas en un solo ejecutivo políico. Desde luego, en España, es, por lo menos, discutible que: (1) se pueda diferenciar claramente un grupo social de los burócratas respecto de un grupo social de elos políticos;; (2) la dificultad se agrava porque la bibliografía española sobre la burocracia tiende a utilizar como criterio definitorio de los burócratas la condición formal de funcionario público.

Por lo que afecta al primer punto, habría que considerar si, en nuestra situación actual, se pueden definir conjuntos de politicos electos y aburócratas. La explicación apela a una serie de procesos; por un lado, la cada vez mayor "profesionalización de la polítican ha borrado el principal determinante de la diferenciación entre políticos electos y funcionarios de nuestro modelo tradicional, más o menos weberiano. Por otra parte, todavía mayor virtualidad en la erosión de la diferenciación tiene el hecho de que un porcentaje muy grande, si no la mayor parte, de nuestros políticos electos son profesionalmente funcionarios públicos. Es ésta una tradición que entre nosotros viene de muy atrás, pero que se intensificó con la Dictadura del General Franco, y todavía más con la democracia. Por tanto, la transposición irreflexiva a nuestra situación de algunos escritos extranjeros aboca a resultados inconsistentes. ¿Cuántos de nuestros políticos electos son profesionales liberales, gentes de empresa o empleados de empresas privadas? Muy evidentemente una pequeña minoría. Casi todos son funcionarios públicos: de la Administración del Estado o de otras Administraciones territoriales; de la Administración civil o de la militar o de la judicial, de los cuerpos generales de la Administración o de cuerpos especiales: médicos, profesores, abogados, ingenieros, economistas, etc., etc. (No es preciso mucho conocimiento para constatar 
que, coeteris paribus, los funcionarios públicos en España se encuentran en una posición de ventaja comparativa para dedicarse a la política). Por si fuera poco, la diferenciación entre politicos, sometidos a la contingencia de la elección, y funcionarios, profesionalizados $\mathrm{e}$ inamovibles, parece estar sufriendo una erosión adicional como consecuencia, precisamente, de los desarrollos "reformistas", particularmente respecto de la categoría de «directivos públicos", que ofrecen oportunidades de acrecimiento del papel del patronazgo de los políticos, a través del incremento de la discrecionalidad en el nombramiento de los altos funcionarios, lo que permite aventurar un mecanismo adicional de confusión entre políticos y burócratas (cuestión analiticamente distinta es que, entre nosotros, el poder de patronazgo degenere pura y simplemente en nepotismo, cuestión que ha de tomarse muy seriamente pues remite a elementos que parecen muy arraigados en la cultura política y organizativa española, identificables o próximos al complejo de actitudes que, hace ya tiempo, BANFIEID calificó en referencia a la Italia del Sur como amoralismo familiar).

Por lo que afecta al segundo punto, ¿quiénes son los burócratas? Del conjunto de la bibliografía se desprende la imagen de la burocracia como una hidra de cien cabezas. Pero, hidra o no, evoca significaciones discernibles. Quizá, las dos más características son, al límite, incompatibles. Por un lado, la más próxima a la visión popular peyorativa de la burocracia (la visión que probablemente evoca la expresión red tape, y sin duda nuestro "vuelva usted mañanan), trasluce una imagen de los burócratas como "funcionarios" (con el valor también preferentemente negativo que se asocia la palabra en este contexto), con competencias de mera ejecución de las decisiones de los legisladores o de los políticos ejecutivos, individuos perezosos y poco competentes, entregados a un ritualismo esterilizante, cuyos objetivos principales son el status y el salario (actual y aplazado, esto es, la pensión). Su poder es, pues, meramente obstativo, y su ideal llegar a la jubilación con la máxima categoría y la mayor pensión posible, por rigurosa antigüedad, habiendo trabajado lo menos posible. En esta visión, la aburocracia. es exclusiva de las Administraciones públicas. Por otro, los burócratas son considerados expertos, no necesariamente menos diligentes en el trabajo que los políticos, o más en general sus "principales"; su función más relevante es la de consultores de éstos, pero, sobre todo, en las Administraciones públicas suelen realizarla mal. Por su formación e inserción profesional propenden a olvidar los fines originarios de la organización, convirtiendo la persistencia de la organización en un fin en sí (MICHELS), o privilegiando ciertos medios sobre los fines, edesplazamiento de fines. (MERTON, 1992) (1968). Su poder dista de ser meramente obstativo. Gracias a su know how y a su identificación con la organización se convierten en un "cuarto poder, o elemento* del gobierno.
En los estudios españoles ha predominado el criterio jurídico de definición, pero el resultado no aboca a mayor claridad. ¿Son burócratas todos los funcionarios públicos?, ¿sólo los funcionarios públicos de mayor categoría, mayor categoría que podemos operacionalizar, por ejemplo, recurriendo al nivel retributivo?, ¿sólo los funcionarios públicos que se ocupan de tareas de administración?, ¿los funcionarios públicos que se ocupan exclusivamente de tareas de administración, pero sólo los de nivel elevado? Desde luego aquel criterio no parece muy útil para individualizar un actor colectivo, con alguna consistencia social. En España, por ejemplo, la mayor parte de los médicos y de los profesores, de los distintos niveles de la enseñanza, son funcionarios públicos, pero ¿esta condición legal es suficiente para asimilarlos, en cuanto a los procesos de socialización que han experimentado, a los valores de que participan, en particular respecto del etbos del servicio público, a sus intereses corporativos, etc., a los funcionarios de la Administración general? ¿En referencia a los mismos parámetros son asimilables los funcionarios de la Administración general a los de cuerpos técnicos específicos, de abogados, ingenieros, etc., al servicio de la Administración? Una respuesta positiva implicaría que un Catedrático de Medicina, un Ingeniero de Minas al servicio de la Administración, un Abogado del Estado y un Técnico Superior de la Administración General del Estado, habrían experimentado procesos de socialización, participarían de valores y tendrían intereses más comunes entre sí, que el Catedrático de Medicina con un Médico no funcionario, el Ingeniero de Minas, con un Ingeniero no funcionario, o el Abogado del Estado con un Abogado no funcionario. Sin embargo, esta suposición parece contraria a la lógica y a la experiencia (puede imaginarse, sin mucha dificultad que los profesores o médicos al servicio de la Administración viesen sustituida su condición de "funcionario público" por otra de personal laboral, y no parece presumible que un cambio de su estatuto jurídico fuese a afectar decisivamente a su papel y funciones).

Volviendo a la relación entre burócratas (considerando tales a los funcionarios con competencia profesional cualificada que realizan funciones generales de administración o técnicas, estos últimos preferentemente en las ramas de la Administración que producen outputs autoritarioss) y políticos, quiero hacer una observación final (que reitera, en parte, lo ya dicho). Es hoy irrealista contraponer al burócrata la imagen de un político dilettante, en abierta posición de inferioridad ante la condición de experto del primero. La profesionalización de la política no sólo implica que los políticos electos, o nombrados, suelen tener particulares experiencia y competencia en la negociación de objetivos y en la inducción en el personal a su servicio de conductas conformes a aquellos objetivos, sino también una relativa especialización en ramos de gobierno o administración. Salvo los líderes principales, que pueden aspirar a la Presidencia del Gobiemo, las expectativas de un candidato a Ministro o 
Secretario de Estado no son iguales en un ramo que otro (Pérez puede tener serias probabilidades de ser Ministro de Educación y ninguna de ser Ministro de Industria). Además, los políticos que llegan a puestos ejecutivos con experiencia parlamentaria, ya han vivido un proceso de especialización, por lo general bastante definida, en el trabajo en Comisiones Parlamentarias. Finalmente el encuadramiento partidista, con frecuencia, les ha dotado de experiencias en la burocracia. partidista y, en todo caso, les ofrece un marco de asesoramiento técnico al margen de la burocracia pública de carrera. Por todo ello, la imagen del "pobre. político desvalido ante el know bow del .resabiado burócrata es en gran parte anacrónica. Y, si le resta- se algo de realismo, en España, al menos, le quedan todavía diversos medios para eludir el poder de los burócratas (en su función de consultores); el primero, el recurso al edirectivo público, ya aludido; el segundo, los asesores políticos, esto es, un staff no de carrera (que no tiene por qué reducirse a la función hoy bastante común de mantener, por nepotismo familiar o de partido, con recursos públicos a unos cuantos parásitos), y el tercero, los contratos de asistencia técnica, maravilloso ábrete sésamo", que igual sirve para un roto que para un descosido y que ofrece tesoros insospechados (cuya consideración sería aquí impertinente).

\begin{abstract}
- Universidad de Santiago de Compostela.
1 Fui invitado como discussant del profesor Vincent Wright. Fue una tarea muy dificil, pues mis opiniones sobre estas cuestiones se inspiran grandemente en las del citado profesor. Con frecuencia, esto más que una discusión es una perífasis.

' Con todo, aunque puede resultar obvio, conviene advertir (no vaya a ser que, por obvio, se olvide) sobre la posibilidad de equivocos en la utilización de la bibliografia en lengua inglesa. Cuando se usa en inglés la palabra administration no siempre tiene el valor de la administración. espanola; por ejemplo, si leemos que Clinton's administration ha adoptado políticas restrictivas de la inmigración ilegal debemos entender que el .gobierno de Clinton... (ni siquiera es así, pero no es cosa de detenerse aqui en cuestiones de traducción y semántica). Lo mismo pasa con la palabra govermment. Cuando PETERS (1996a y 1996b) habla de cuatro modelos de government no podemos traducir por agobiemo• en el sentido español. En este caso es más difíicil todavia, pero la palabra espanola más próxima sería •Administración.
\end{abstract}

' Un ejemplo significativo: Improving Public Management, de METCALFe y RUCHARDS (1987) ha sido traducido por La Modernización de la gestión Priblica (Madrid, Instituto Nacional de Administración pública, 1989).

1 En la bibliografia francesa TrosA (1992).

- Brabant (1992: 57), define la modemización administrativa como una puesta al día permanente de la Administración, en función de las exigencias del momento y del lugar.

"A veces apenas son reformas, aunque el ánimo de exhaustividad de los estudiosos lleve a calificarlas como tales. Por ejemplo, WRIGHT (1994: 103) enumera como un caso de reforma, la transferencia de Bonn a Berlin de la sede de algunos ministerios federales. Una decisión de esta naturaleza poco parece tener que ver con, por ejemplo, los programas de reforma británico u holandés.

' Lo que ha tenido más éxito entre nosotros ha sido la demonización de estas inspiraciones; en particular, la demonización de la Sra. Thatcher. Hay toda una infra-literatura, de discursos políticos y escritos de intelectuales y periodistas de izquierda y -progres (por lo general, con muy escaso conocimiento de la políica británica, lo que es bastante lógico) expresiva de esta demonización. El demonio, en sus múltiples encamaciones, y sus epígonos menores, que suelen ser multitud, no sólo comete maldades, sino que comete maldades gratuitas (por el mero placer de fastidiar). De ahi que siempre se pueda esperar de él una maldad adicional y que, por tanto, cualquier nueva catástrofe le sea razonablemente imputable. Así, la Sra. Thatcher no es sólo responsable de las consecuencias de sus políticas, que lógicamente no nos afectan, de la inspiración de politicas similares en España, que sí nos afectan, pero también de cualquier politica tperversa. que se le ocurra a la derecha española: el demonio nunca duerme. (la documentación de este juicio desborda el marco de este articulo; remito a los incrédulos. a una excursión por nuestras hemerotecas).

${ }^{8}$ Es antigua, y particularmente relevante desde mediados del siglo pasado, la polémica respecto de si las estructuras, procesos y opciones políticas dependen de condiciones extrapolíticas (preferentemente de tipo económico y/o -social.) o si, por el contrario, dependen de elecciones autónomas respecto de aquéllas. A la vista de la experiencia, hoy parece razonable excluir cualquier determinismo económico o social de la realidad política; pero parece también igualmente razonable entender que la autonomía de configuración de la realidad politica, la posibilidad de elección entre diversas opciones está limitada por el entomo económico-social. No todo es políticamente posible en un momento y lugar dados.

' Sin embargo, de hecho, como atestiguan numerosos estudios empíricos, la participación de los burócratas en la elaboración de políticas es muy relevante. Ver ABER BaCH, Putnam y Rockman, 1981; para España, Olmeda, 1988. Por otra parte, como siempre que se habla en términos muy generales, las diferencias entre los oradores son muy grandes: por ej., ROSE (1991: 13) subraya la unidad entre decisores politicos y burócratas que se da en la Europa continental frente a su artificial (sic) dicotomia en los paises angloamericanos.

in En la mesa redonda sobre La calidad de la democracia, coordinada por Julián San. tamaría, en la sesión plenaria del I Congreso de la Asociación Española de Ciencia Política y de la Administración, Bilbao, 6 de diciembre de 1994, expuse ya mi opinión sobre los efectos no deseables de un énfasis garantista. respecto de la actuación de la Administración (puede verse un resumen en el libro programa del Congreso).

"Conviene, sin embargo, advertir que uno de los corolarios más frecuentes de los regímenes de prestación en concurrencia por organizaciones públicas y privadas es que no se logre una unidad real de mercado, sino una simple yuxtaposición de mercados segmentados. Por ejemplo, esto es, aproximadamente, lo que ocurre en España con la educación universitaria: las Universidades públicas no compiten entre si (entre orras razones no pueden competir por las limitaciones que supone para la libertad de elección del estudiante la institución del distrito universitario.), pero tampoco compiten con las privadas, que, en su mayor parte, se especializan en la captación de estudiantes que fracasan en su acceso o permanencia en las Universidades públicas. 


\section{Bibliografia}

ABERBACH, Joel D., Putnam, Robert D. y Rockman, Bert A. (1981): Bureaucrats and Politicians in Western Democracies, Cambridge (Mass.)/London, Harvard Univ. Press.

ABRAHumson, Eric (1996): -Management fashion, Academy of Management Review, vol. 21, n. 1, pp. 254285.

BLAU, Peter M. y MFYeR, Marshall W. (1971): Bureaucracy in Modern Society, 2." edic., New York, Random House.

BralBaNt, Guy (1992): -Qu'est-ce que la modemisation, Revre Francaise d'Administration Publique, n. 61 , enero-marzo.

CAIDEN, Gerald E. (1991): Administrative Reform Comes of age, Berlin/New York, Walter de Gruyter.

Canales, José Manuel (1994): El control de la gestión pública, en Manuel Arenilla, ed., Gasto puiblico y crisis económica, Santiago de Compostela, EGAP, pp. 55-77.

GoODSEll, Chartes T. (1994), The Case for bureaucracy. A public Administration polemic, 3." edic., Chatham (New Jers.) Chatham House.

Harari, Oren (1997): ••Por qué murió la reingenieria?? (rad. de •Why Died Reenginering Die?., Management Review), Harvard Deusto o Business Review, n." 77, marzoabril, pp. 26-30.

HolcomBE, Randall G. (1978): PPublic Choices and Public Spending, National Tax Joumal, vol. XXXI, n." 4, diciembre, pp. 373-383.

Hummel, Ralph (1994): The Bureaucratic experience. A critique of life in the modem organization, New York, St. Marin's Press.

Margous, Julius (1995): •A Comment on the Pure Theory of Public Expenditure, The Review of Economics and Statistics, vol. XXXVII, noviembre, pp. 347-349.

MERTON, Robert K. (1992): Teoria y estructura sociales, 3.' edic., México, Fondo de Cultura Económica (trad. de Social Theory and Social Structure, 3.' edic., Glencole, Ill., The Free Press, 1968).

METCALFE, Les y RiCHARDS, Sue (1987): Improving Public Management, London/Newbury Park, Sage Publ.

MISES, Ludwig von (1962): Bureaucracy, 2.' edic., Yale University Press.

NiETo, Alejandro (1989): :Reforma administrativa y modernización de la Administración pública: cun problema pendiente?., en Instituto Vasco de Administración Pública, Modernización Administrativa, Onati, pp. 101-115.

NISKANEN, Jr., WILIAM, A.S. (1971): Bureaucracy and Representative Government, Chicago, Aldine Publ. Co.
OLMEDA, José A. (1988): Las Fuerzas Armadas en el Estado franquista: Participación politica, influencia presupuestaria..., Madrid, El Arquero.

OSBORNE, David y GAEBLER, Ted (1994): La reinuención del gobiemo, Barcelona/Buenos Aires, Edic. Paidós (trad. de Reinuenting Govermment, Reading, Mass., AddisonWesley Publ. Co. 1992).

PETERS, B. Guy (1991): -The European bureaucrat: The applicability of "Bureaucracy and representative govemment" to non-American settings, en André BLAs y Stéphane Dion, eds., The budget-maximizing bureaucrat, Univ. of Pitsburgh Press, pp. 303353.

PETERS, B. Guy (1996a): The Future of Governing: Four Emerging Models, Lawrence, University Press of Kansas.

PETERS, B. Guy (1996b): :Democracy and Administration: The Varieties of Administrative Reform. (Conferencia de Apertura del II Congreso de la Asociación Española de Ciencia Política y de la Administración), Fac. de CC. Políticas y Sociales. Univ. de Santiago de Compostela, s.a. (1996) (mimeo).

RiGBY, Darrell (1993): -The Secret History of Process of reengineering, Planning Review, abril, pp. 2427.

RosE, Richard (1991): .Prime Ministers in Parliamentary Democracies, West European Politics, vol. 14, n. 1, abril, pp. 9-24.

Samuelson, Paul A. (1954): -The Pure Theory of Public Expenditure, The Review of Economics and Statistics, vol. XXXVI, noviembre, pp. 387-389.

TrosA, Sylvie (1992): .La modemisation est-elle evaluable?, Politiques et Management Public, vol. 10, n. 4 , diciembre, pp. 65-83.

VEBLEN, Thorstei (1904): The Theory of Business Enterprise, New York, Charles Schibners Sons, reimpr. facsimilar, Clifton, Augustus M. Helley Publ. 1973.

VILAs, Nogueira J. (1996): . O gasto público como condicionante de estratexias politicas globaiss, Revista Galega de Aministración Priblica, n." 14, Santiago, septiembre-diciembre, pp. 85-106.

WRIGHT, Vincent (1994): Reshaping the State: The Implications for Public Administration, West European Politics, vol. 17, n. 3, julio, pp. 102-135.

WRIGHT, Vincent (1995): -The Paradoxes of Administrative Reform, en Walter J.M. KICKERT, ed., Public Management and Administrative Reform in Europe, Cheltenhiam, UK/Lyme, US, Edward Elgar, pp. 7-13. 